\title{
FEB 61983
}

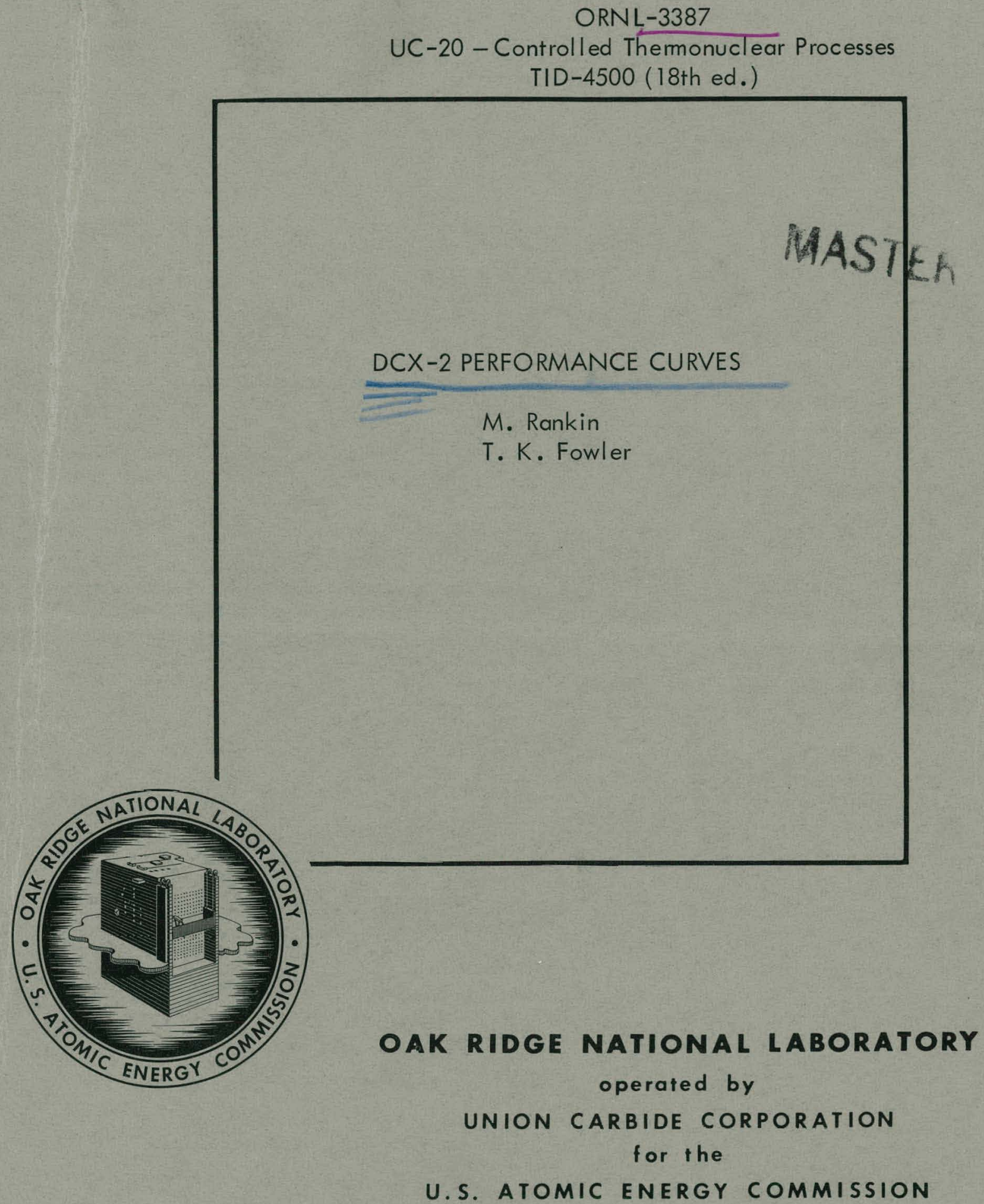




\section{DISCLAIMER}

This report was prepared as an account of work sponsored by an agency of the United States Government. Neither the United States Government nor any agency Thereof, nor any of their employees, makes any warranty, express or implied, or assumes any legal liability or responsibility for the accuracy, completeness, or usefulness of any information, apparatus, product, or process disclosed, or represents that its use would not infringe privately owned rights. Reference herein to any specific commercial product, process, or service by trade name, trademark, manufacturer, or otherwise does not necessarily constitute or imply its endorsement, recommendation, or favoring by the United States Government or any agency thereof. The views and opinions of authors expressed herein do not necessarily state or reflect those of the United States Government or any agency thereof. 


\section{DISCLAIMER}

Portions of this document may be illegible in electronic image products. Images are produced from the best available original document. 
Printed in USA. Price: $\$ 0.50$ Available from the

Office of Technical Services

U. S. Department of Commerce

Washington 25, D. C.

\section{LEGAL NOTICE}

This report was prepared as an account of Government sponsored work. Neither the United States, nor the Commission, nor any person acting on behalf of the Commission:

A. Makes any warranty or representation, expressed or implied, with respect to the accuracy, completeness, or usefulness of the information contained in this report, or that the use of any information, apparatus, method, or process disclosed in this report may not infringe privately owned rights; or

B. Assumes any liabilities with respect to the use of, or for damages resulting from the use of any information, apparatus, method, or process disclosed in this report.

As used in the above, "person acting on behalf of the Commission" includes any employee or contractor of the Commission, or employee of such contractor, to the extent that such employee or contractor of the Commission, or employee of such contractor prepares, disseminates, or provides access to, any information pursuant to his omployment or cunlruct with the Commission, or his employment with such contractor. 
Contract No. W-7405-eng-26

THERMONUCLEAR DIVISION

DCX-2 PERFORMANCE CURVES

M. Rankin and T. K. Fowler

DATE ISSUED

\section{JAR 281963}

OAK RIDGE NATIONAL LABORATORY

Oak Ridge, Tennessee

operated by

UNION CARBIDE CORPORATION

for the

U.S. ATOMIC ENERGY COMMISSION 


\title{
DCX-2 PERFORMANCE CURVES
}

\section{Rankin and T. K. Fowler}

\begin{abstract}
This report gives performance curves of steady state ion density versus injected currents for a survey of various parameters. The parameters are $\mathrm{F}_{\mathrm{M}}$, the energy of injected $\mathrm{H}_{2}^{+}$ions; $\mathrm{L}$, the ion path length; and factors $\mathrm{h}$ and $\Gamma$, where $h / \Gamma$ is the fraction of the undissociated portion of the molecular heam not absorbed and $\Gamma$ is taken as 2. Performance curves are also computed assuming the energy transfer rates to be enhanced by arbitrary factors of 10 and 100 .
\end{abstract}

Analyses of the variation of steady state ion density with injected current for gas break-up trapping devices have previously been given by Simon $^{1}$ and Mackin. ${ }^{2}$ A more recent paper by Fowler and Rankin ${ }^{3}$ (herein referred to as $F-R$ ) has made use of ion energy distributions obtained as solutions of the Fokker-Planck equations to provide proper averages of the products of velocity with ion loss and ion destruction cross sections $\left(\overline{\sigma_{\ell} \mathrm{v}}\right.$ and $\left.\overline{\sigma_{\mathrm{d}} \mathrm{v}}\right)$ assumed constant in the former papers. These averages (which are functions of $\alpha$, the fraction of "burnout" of the neutrals)

\footnotetext{
A. Simon, J. of Nuclear Energy: Part C, I (4), 215 (July 1960). ${ }^{2}$ R. J. Mackin, Jr., Nuclear Fusion I(2), 131 (March 1961). 3. K. Fowler and M. Rankin, Energy Distribution of Ions and Electrons in DCX After Burnout: Oracle Code Eddie, ORNI-3161 (August 29, 1961).
} 
were then used with equations governing neutrals to give a DCX-2 performance curve for one particular set of parameters (Fig. 6 of $F^{\prime}-K$ ). This report extends the $F-R$ report first by surveying $\overline{\sigma_{b} v}$ and $\overline{\sigma_{d} v}$ for various values of $\mathrm{E}_{\mathrm{M}}$; the energy of injected $\mathrm{H}_{2}^{+}$ions; the ion path length, $L$; and factors $h$ and $\Gamma$, defined as follows.

Since molecular ions are a source of neutrals, it has been proposed that the undissociated portion of the beam be absorbed. $h / \Gamma$ is the fraction not absorbed, which, together with dissociated ions, eventually result in the return to the system of neutral atoms, $\Gamma$ in number per molecular ion.

We have also computed performance curves assuming energy transfer rates (E.T.R.) to be enhanced by an arbitrary factor, $\beta$, chosen to be 10 and 100. This has been done to indicate the possible effect. of collective phenomena not accounted for with our transfer rates taking into account binary collisions only. Having in mind mechanisms such as the Harris instability in which ion cyclotron motion couples to electron. plasma oscillations, we have increased by the factor $\beta$ only the ionelectron transfer rate, and the electron scattering rate appearing in the electron lose term.

The set of simultaneous equations whose solution (as a function of the parameter $\alpha$ ) gives the performance curves are as follows:

$$
\begin{aligned}
& \text { (1) } h I+\theta_{0} N_{0}+(\Gamma-h) n_{+}^{2} \overline{\sigma_{l} v} v=f\left(\hat{n}_{0}-\alpha_{+}\right) \frac{v_{0}}{l} v+\theta_{0} \hat{n}_{0} \\
& \text { (2) }\left(\hat{n}_{0}-\alpha_{+}\right) \frac{v_{0}}{\ell}=\alpha_{+}^{2} \frac{\overline{\sigma_{d} v}}{\text {. }} \text {. } \\
& \text { (3) } \frac{I}{V}\left\{\frac{\left(\hat{n}_{0}+n_{+}\right) \sigma_{B} L}{I+\left(\hat{n}_{0}+n_{+}\right) \sigma_{B} L}\right\}=n_{+}^{2} \overline{\sigma_{\ell} v} \\
& \text { (4) } \bar{n}_{0}=a_{+}
\end{aligned}
$$


where $\bar{n}_{0}=$ average internal neutral gas (atom) density; $\hat{n}_{0}=$ average external neutral gas (atom) density; and $\mathbb{N}_{0}=$ neutral density in absence of beam or plasma. These equations differ from those given in F-R only by the generalization of equation ( 1 ) by the introduction of $h$. We take $\Gamma=2$.

A cubic equation, $\mathrm{An}_{+}^{3}+\mathrm{Bn}_{+}^{2}+\mathrm{Cn}^{+}+\mathrm{D}=0$, results from combining the four above equations. Here

$$
\begin{aligned}
& \mathrm{A} \equiv \alpha \overline{\sigma_{d} \mathrm{v}} \frac{\ell}{v_{0}}\left(\frac{\alpha \overline{\sigma_{d} \mathrm{v}} f}{\bar{\Gamma}}+\frac{\alpha \theta_{0} \overline{\sigma_{d} \mathrm{v}}}{\Gamma \mathrm{V}} \frac{\ell}{v_{0}}-\overline{\sigma_{\ell} \mathrm{v}}\right) \\
& B \equiv(\alpha+1)\left(\alpha \frac{\overline{\sigma_{d} v} f}{\Gamma}+\frac{\alpha \theta_{0} \overline{\sigma_{d} v}}{\Gamma v} \frac{\ell}{v_{0}}-\overline{\sigma_{\ell} v}\right)+\alpha^{2} \overline{\sigma_{d} v} \frac{\ell}{v_{0}} \frac{\theta_{0}}{\Gamma V} \\
& \mathrm{C} \equiv \alpha \overline{\sigma_{d} v} \frac{l}{v_{0}}\left(-\frac{\theta_{0} \mathrm{~N}_{0}}{\Gamma \mathrm{V}}\right)+(\alpha+1)\left(\frac{\alpha \theta}{\Gamma \mathrm{V}}\right)-\frac{h}{\Gamma} \frac{\overline{\sigma_{l} \mathrm{v}}}{\sigma_{\mathrm{B}} \mathrm{L}} \\
& D \equiv(\alpha+1) \quad\left(-\frac{\theta_{0} N_{0}}{\Gamma V}\right)
\end{aligned}
$$

Physical solutions of (1)-(4) are those with $n_{+}, \hat{n}_{0}, \bar{n}_{0}$ and I positive. I $\alpha$ and $n_{+}$are positive, then by (2)-(3) the other quantities are also positive. Thus, $\alpha$ having been defined positive, $n_{+}>0$ is sufficient for a meaningful solution. Now if coefficient A alone is positive, also $B>0$, and since $D<0$, there is one and only one positive root, $n_{+} \cdot$ We have found that if $A<0$, there is no positive solution. The condition $A>0$ places a lower limit on the burnout fraction $\alpha$, approximately

(5) $\quad \alpha_{\min } \sim \frac{\Gamma}{f} \frac{\overline{\sigma_{\ell}^{v}}}{\overline{\sigma_{d} v}}$

This limitation on burnout can be understood as follows. In the limit of large current, the dissociation is complete, and the molecular beam 
is the principal source of neutrals, all of which are pumped by the plasma. The neutrals are supplied at rate $(\Gamma / f) I$ and trapped ions are supplied at rate $I$, each proportional to $I$. Thus, $\alpha=\bar{n}_{0} / n_{+}$is given by $\Gamma / f$ times the reciprocal of the ratio of loss rates, which is just equation (5). Once this limit is reached, $\alpha$ remains the same for all greater I.

Points on the performance curves as a function of $\alpha$ were calculated by an IBM 7090 code. Two numerical difticulties may be mentioned. For Emall values of $\alpha$ approaching the limiting condition, degeneration of the cubic equation to a quadratic equation takes place with a loss in accuracy of the solution to the cubic. In this case, solutions are easily found from the quadratic equation. For small $\alpha$ and $h$, equation (I) is subject to errors in taking the difference of large, nearly equal, quantities and $I$ is more reliably calculated from equation (3).

Figure 1 gives $\overline{\sigma_{\ell}^{v}}$ and $\overline{\sigma_{d} v}$ as functions of $\alpha$ for $\mathrm{F}_{\mathrm{M}}=200,400$, 600 , and $800 \mathrm{kev}$. Figure 2 gives $\overline{\sigma_{\ell} \mathrm{v}}$ and $\overline{\sigma_{d} \mathrm{v}}$ as functions of $\alpha$ for $F_{M}=600 \mathrm{kev}$ and for the enhanced energy transfer rates of 10 and 100 .

Performance curves are included as follows:

Figure 3: Variation of molecular ion energy for $L=50 \mathrm{~m}$ and $\mathrm{h}=2$.

Figures 4-7: Variation of path length for $h=2$ and $E_{M}=200$, 400,600 , and $800 \mathrm{kev}$.

Figures 8-11: Variation of path length for $h=.001$ and $F_{M}=200$, 400,600 , and $800 \mathrm{kev}$.

Figure 12: Variation of energy transfer rate for $h=2$ and $E_{M}=600 \mathrm{kev}$. 
The parameters $l / v_{0}=.1389 \times 10^{-3} \mathrm{sec}, f=.8, \mathrm{~V}=10^{5} \mathrm{~cm}^{3}, \theta_{0}=10^{6}$ $\frac{\mathrm{cm}^{3}}{\mathrm{sec}}$, and $\mathrm{N}_{0}=7 \times 10^{9}\left(\frac{\#}{\mathrm{~cm}^{3}}\right)$ are the same in all graphs.

For convenience in understanding the influence of various parameters, we give the following table of upper critical currents.

Table I. Critical Current (U.C.C.)

Variation With Injection Energy, $\mathrm{F}_{\mathrm{M}}$

For $\mathrm{L}=50 \mathrm{~m}$

\begin{tabular}{cc}
\hline $\mathrm{E}_{\mathrm{M}}(\mathrm{kev})$ & U.C.C. (ma) \\
\hline 800 & 19 \\
600 & 73 \\
400 & 920 \\
200 & 29,000 \\
\hline
\end{tabular}

Variation With L, Undissociated Ions Absorbed

\begin{tabular}{cc}
\hline For $h=.001$ and $\overline{\mathrm{E}}_{\mathrm{M}}=600 \mathrm{kev}$ \\
\hline $\mathrm{L}$ (meters) & U.C.C. (ma) \\
\hline 100 & 3.3 \\
50 & 6.8 \\
20 & 17 \\
10 & 33 \\
\hline
\end{tabular}

\begin{tabular}{cc} 
Variation With Path Length, I \\
\hline For $h=2$ and $E_{M}=600 \mathrm{kev}$ \\
\hline$L$ (meters) & U.C.C. (mi) \\
\hline 100 & 20 \\
50 & 73 \\
20 & 420 \\
10 & 1450 \\
\hline
\end{tabular}

Variation With Arbitrary Increasc in Energy Transfer Rate (E.T.R.) by Factor $\beta$

\begin{tabular}{|c|c|}
\hline$\beta$ & U.C.C. (ma) \\
\hline 1 & 73 \\
\hline 10 & 330 \\
\hline 100 & 1500 \\
\hline
\end{tabular}

The authors wish to acknowledge the helpful work of Mr. D. A. Griffin in preparation of the curves. 


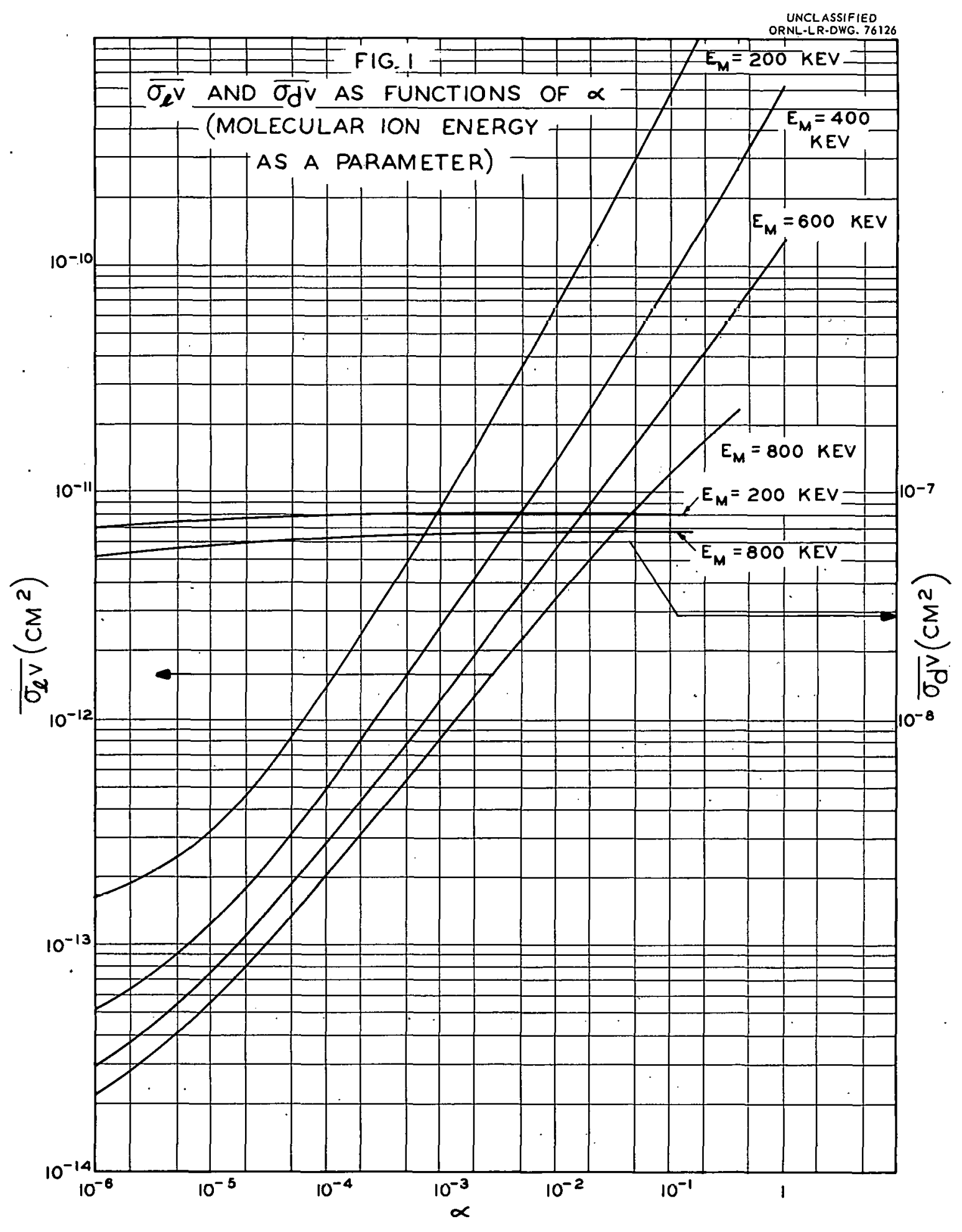




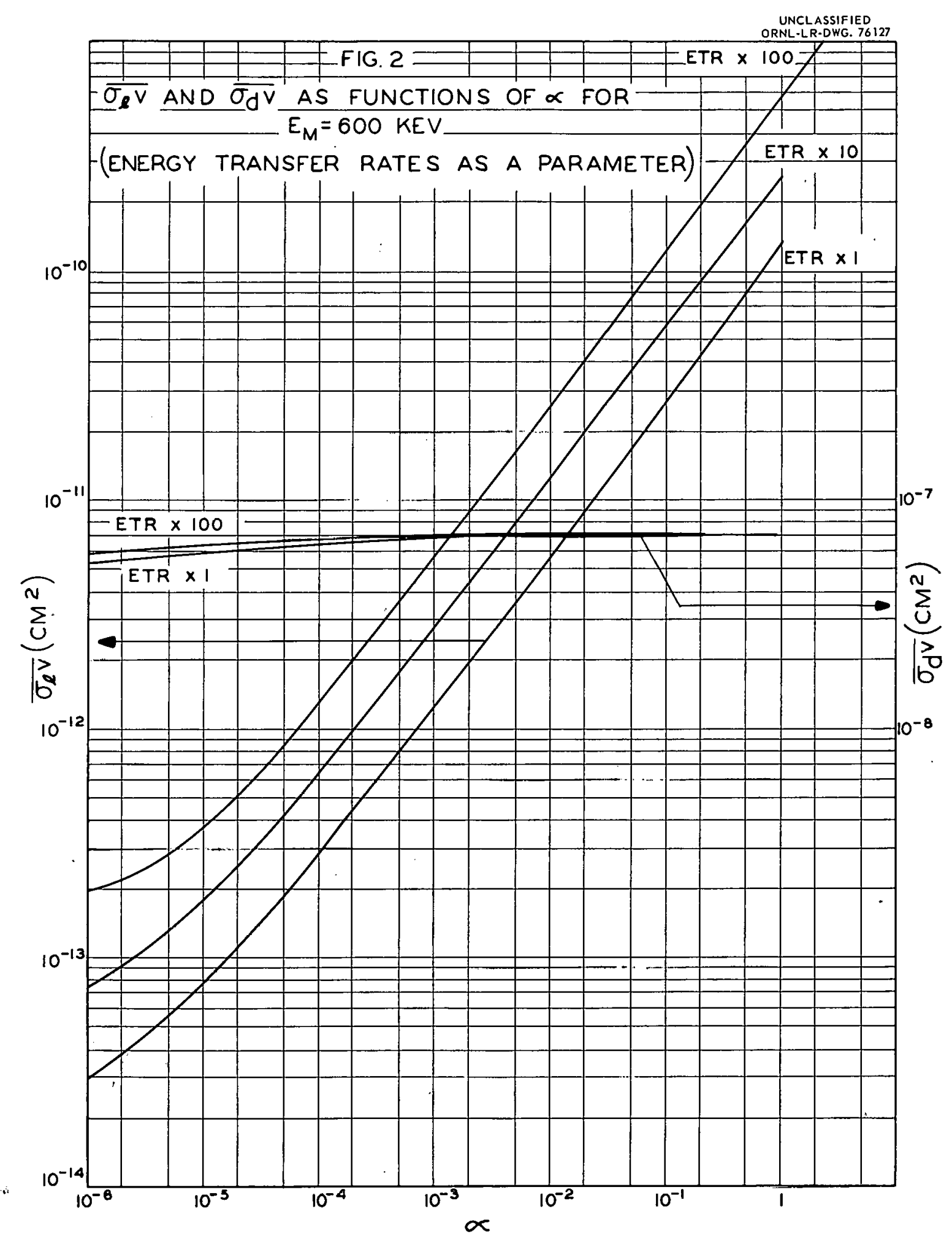




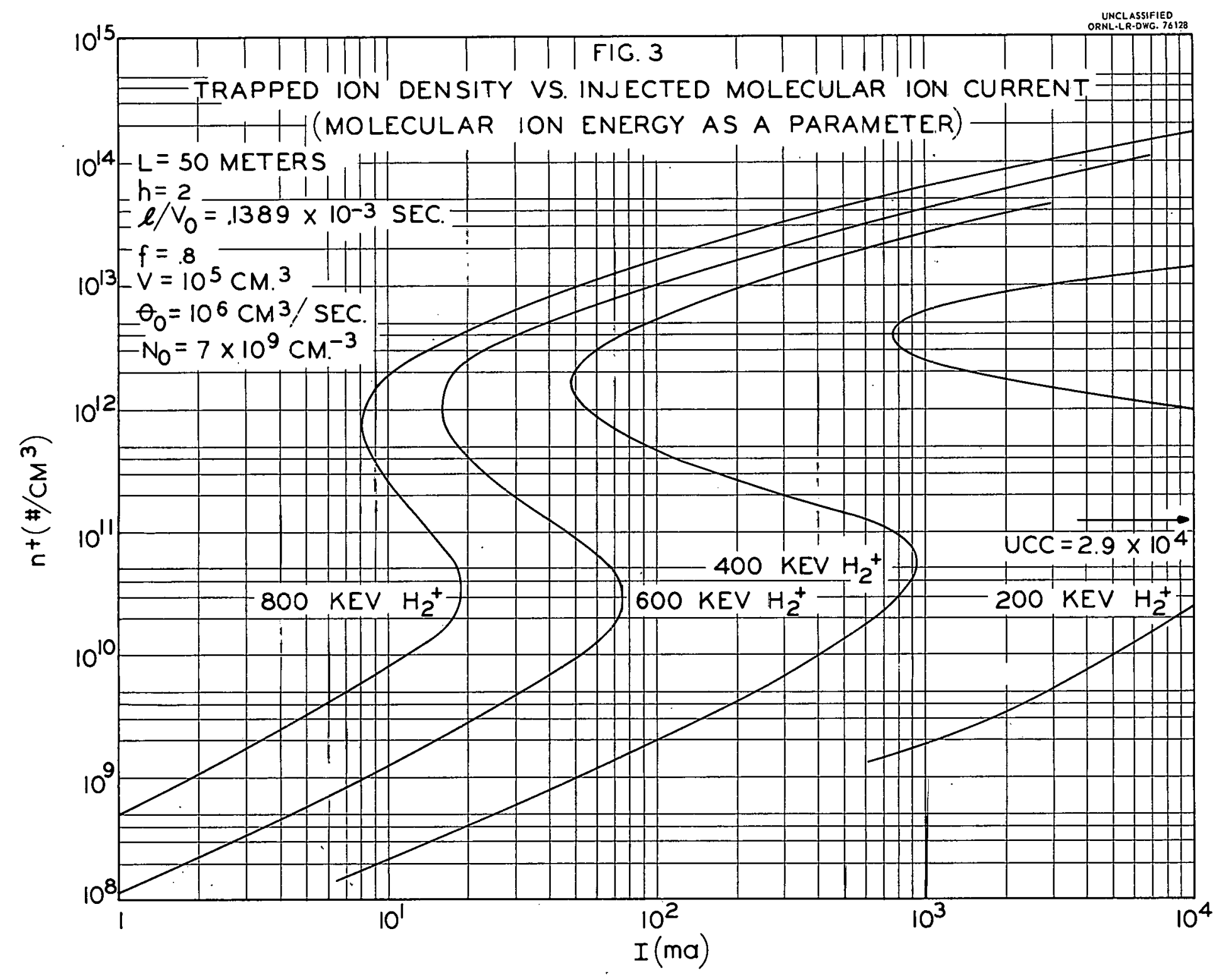




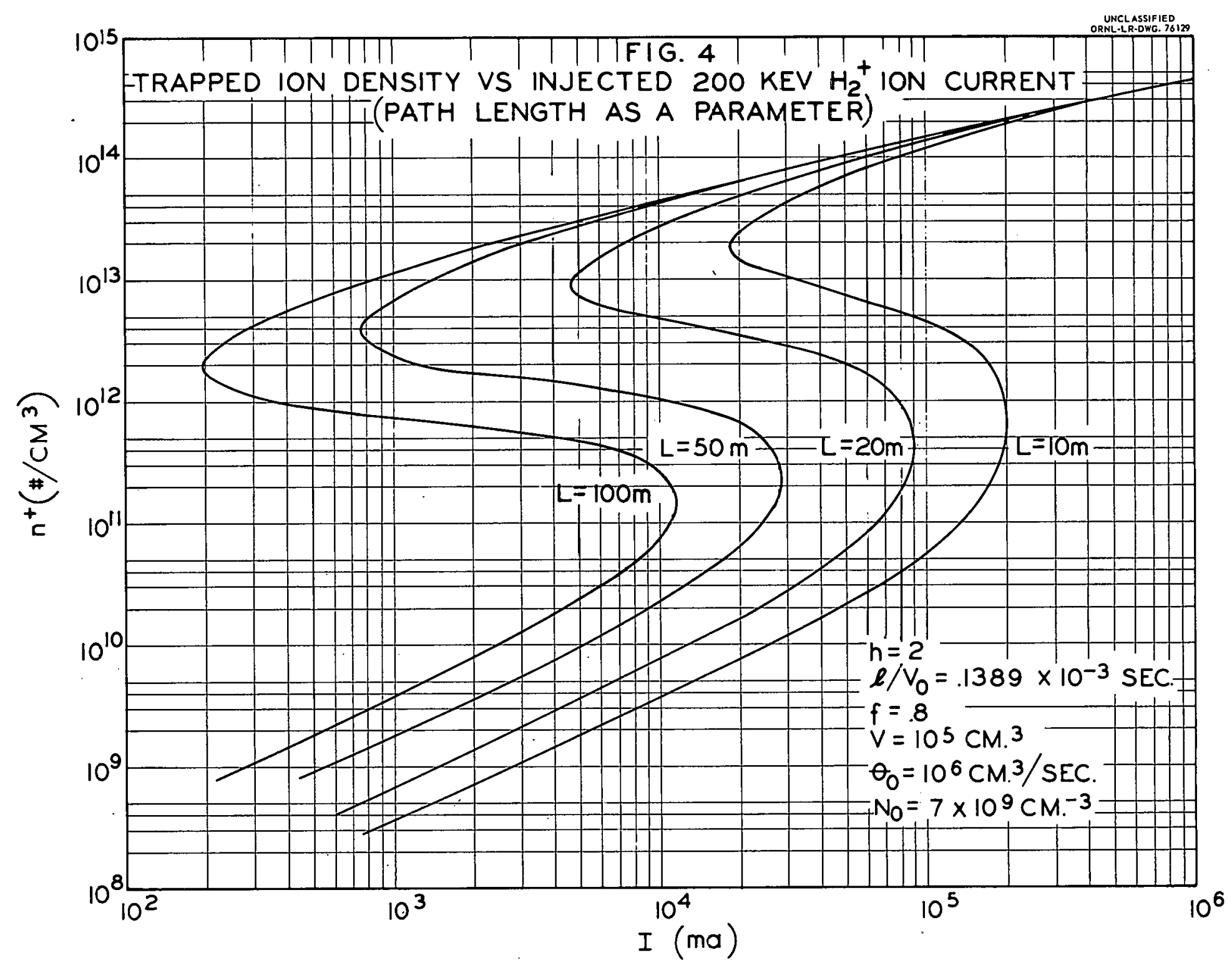




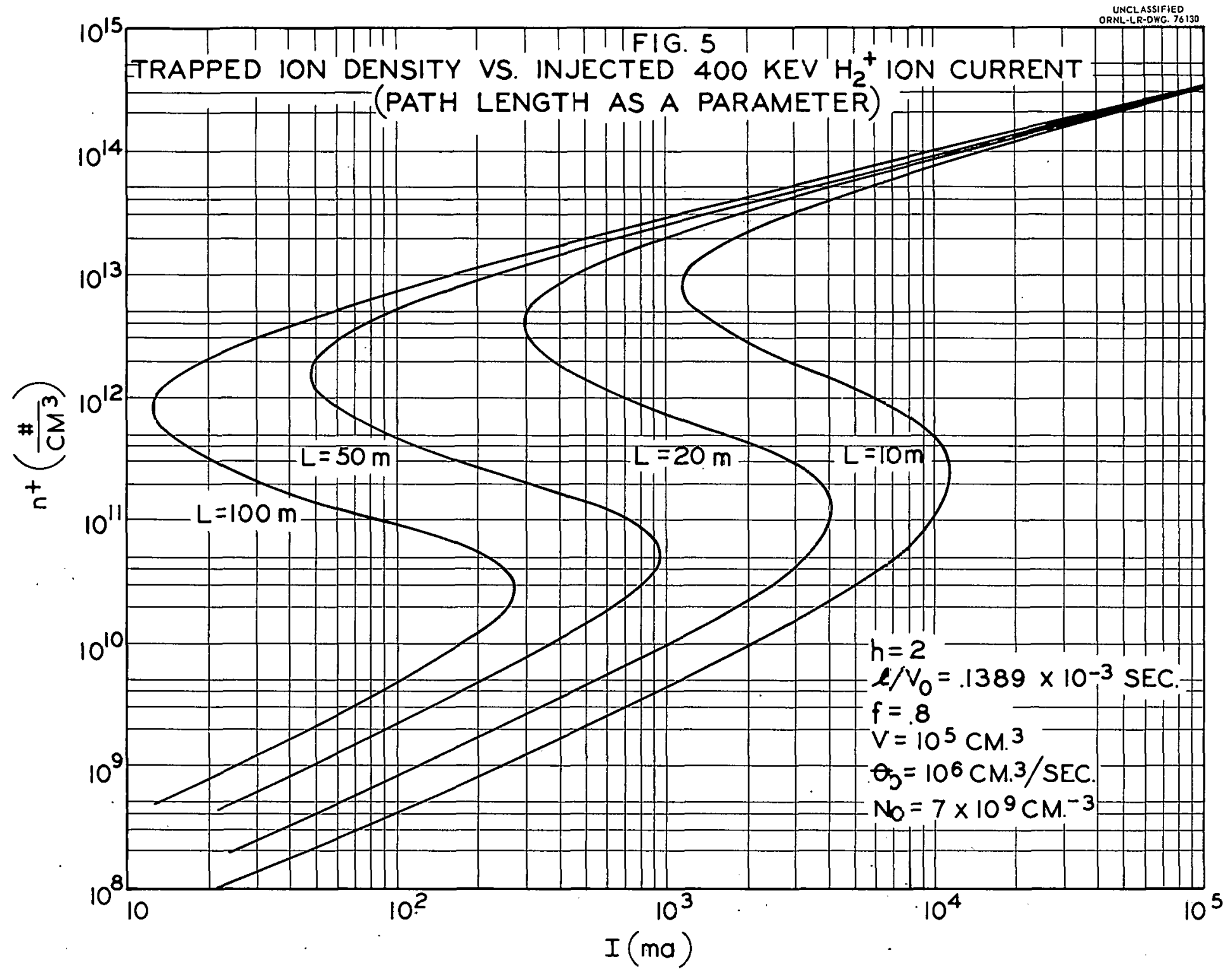




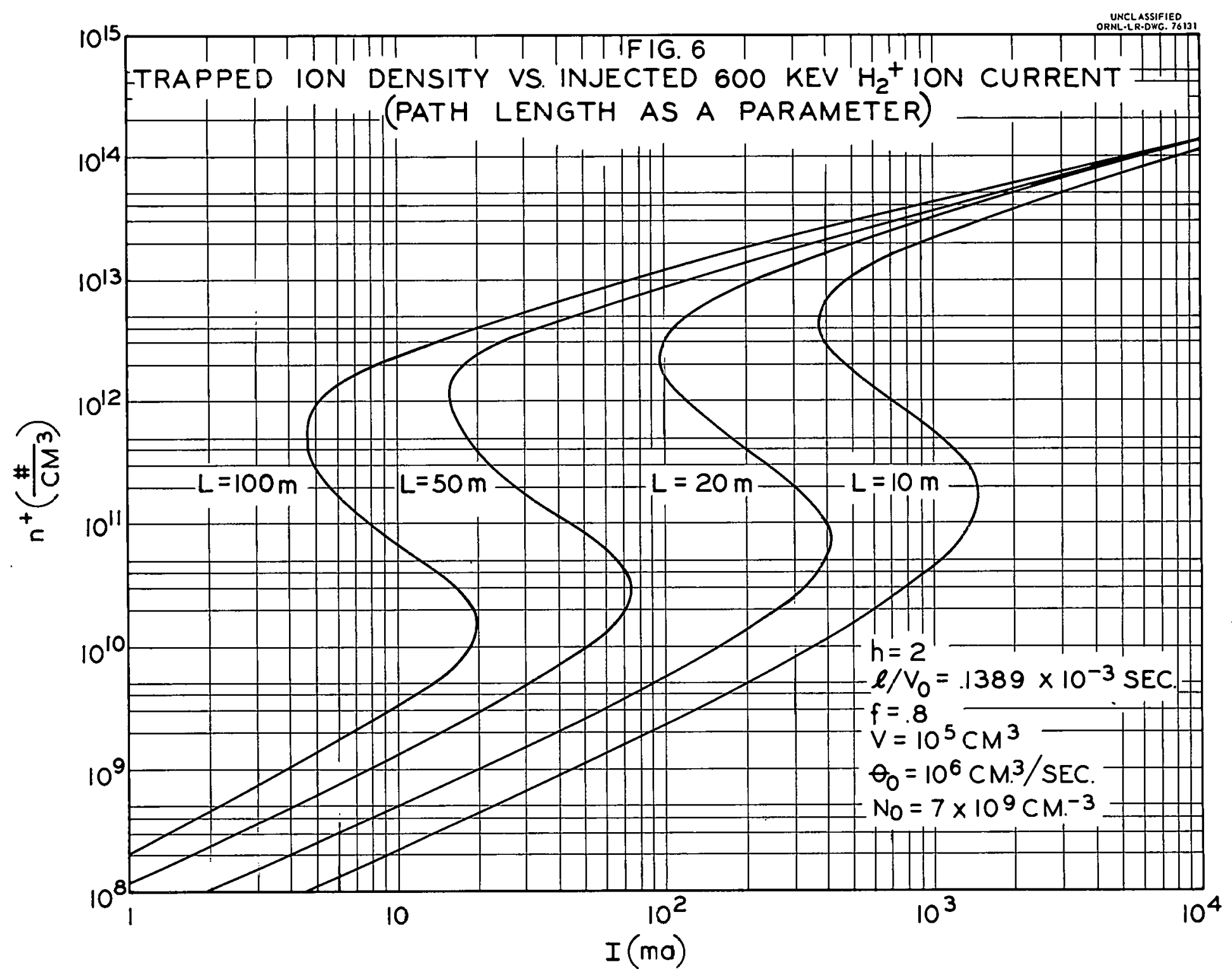




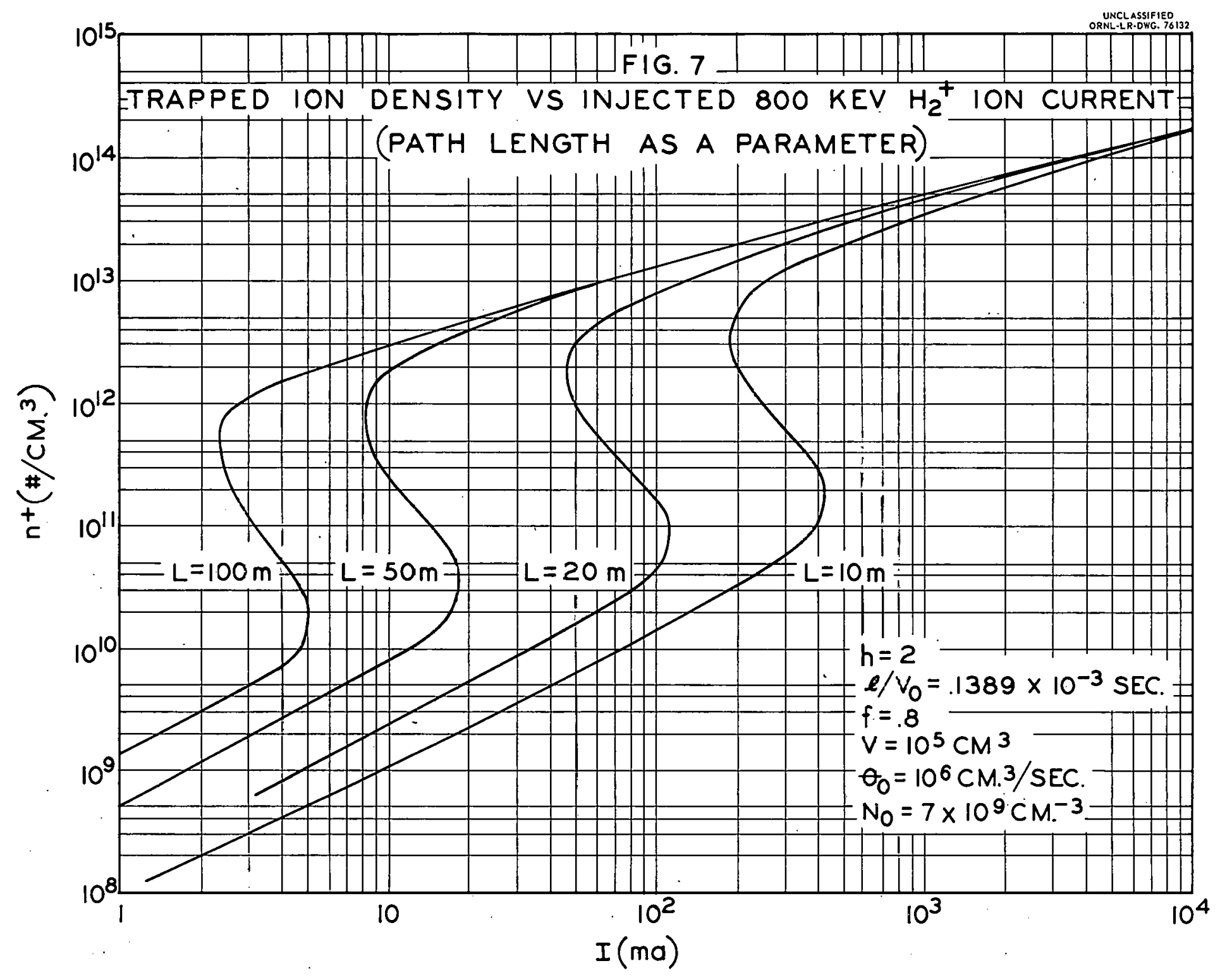




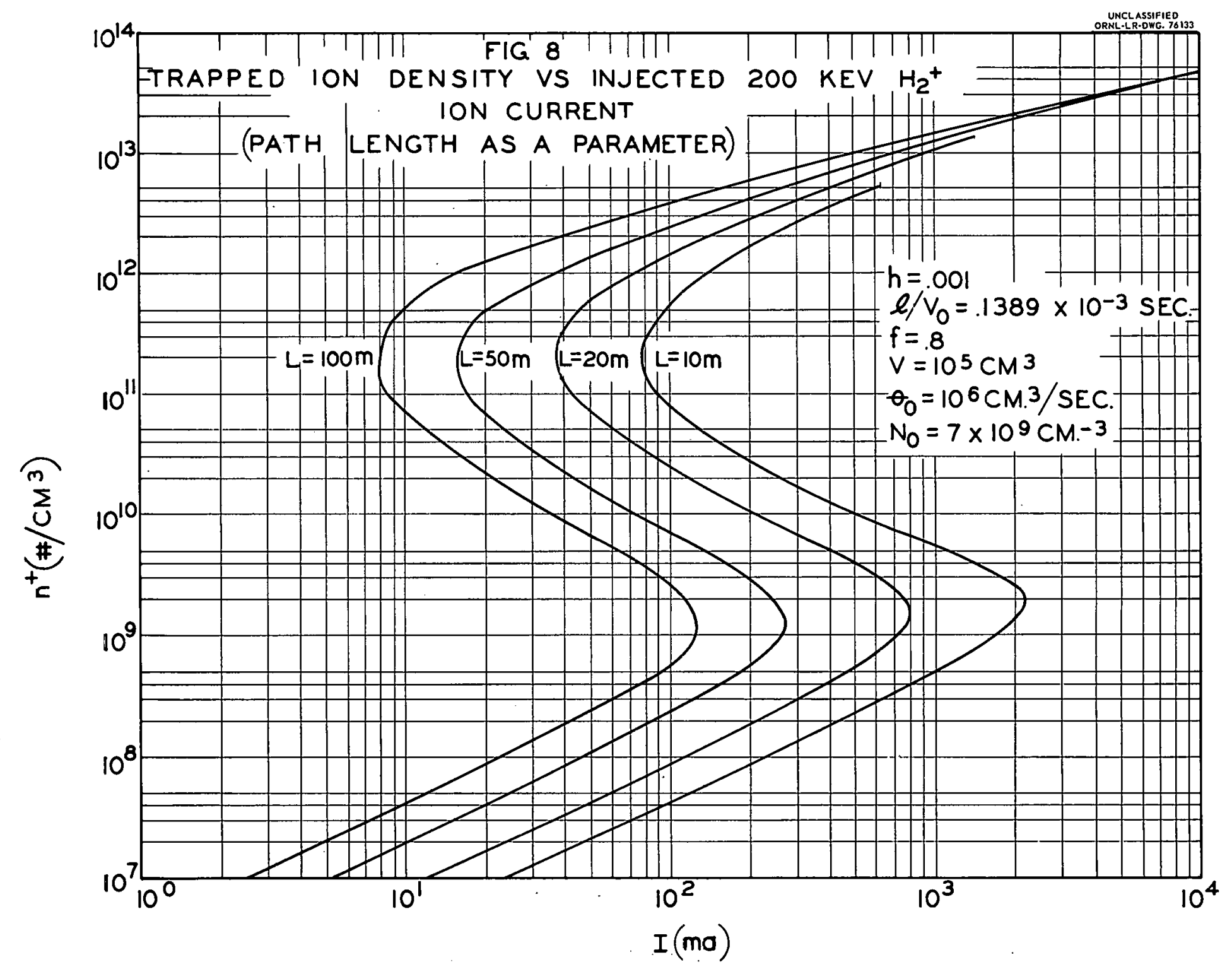




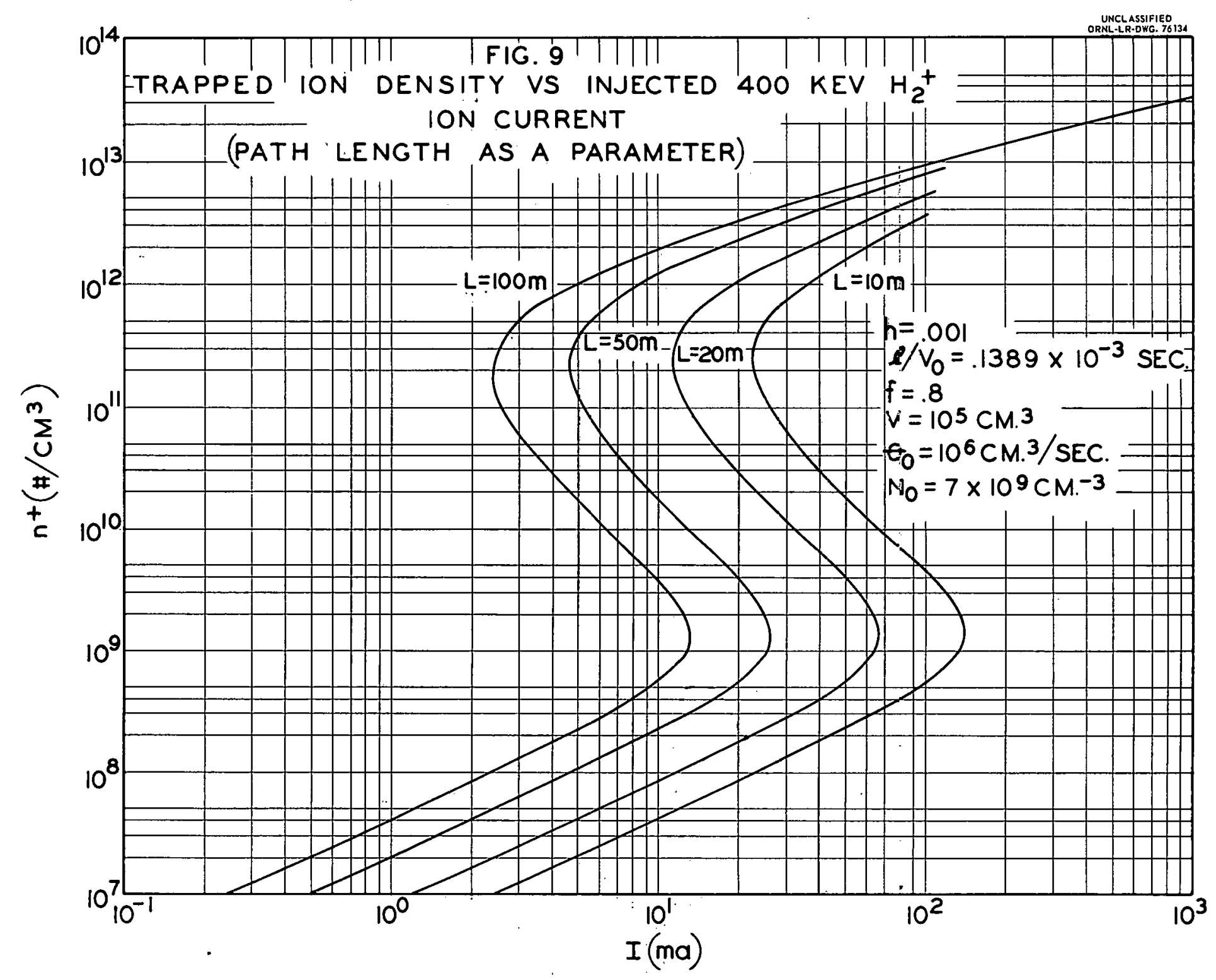




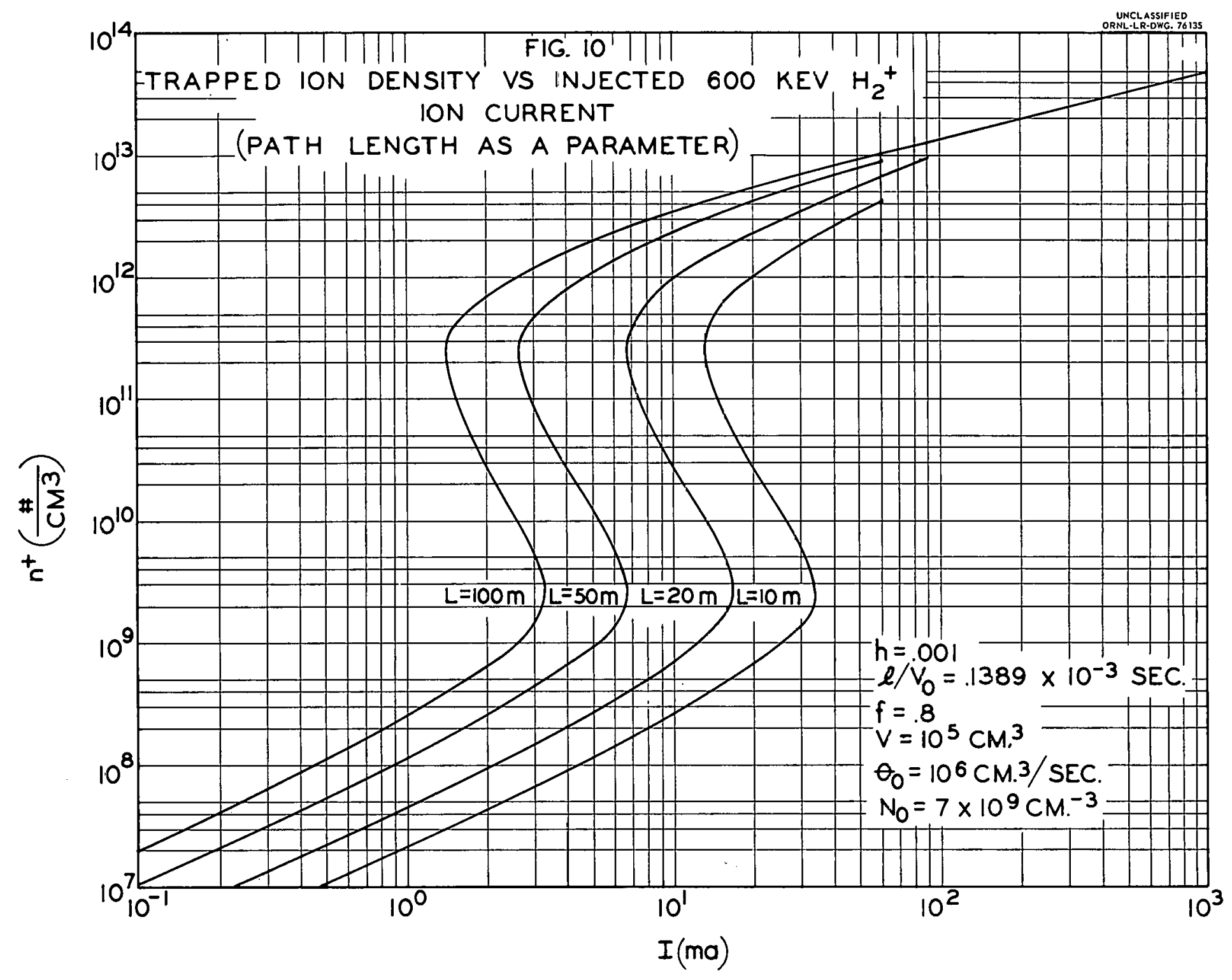




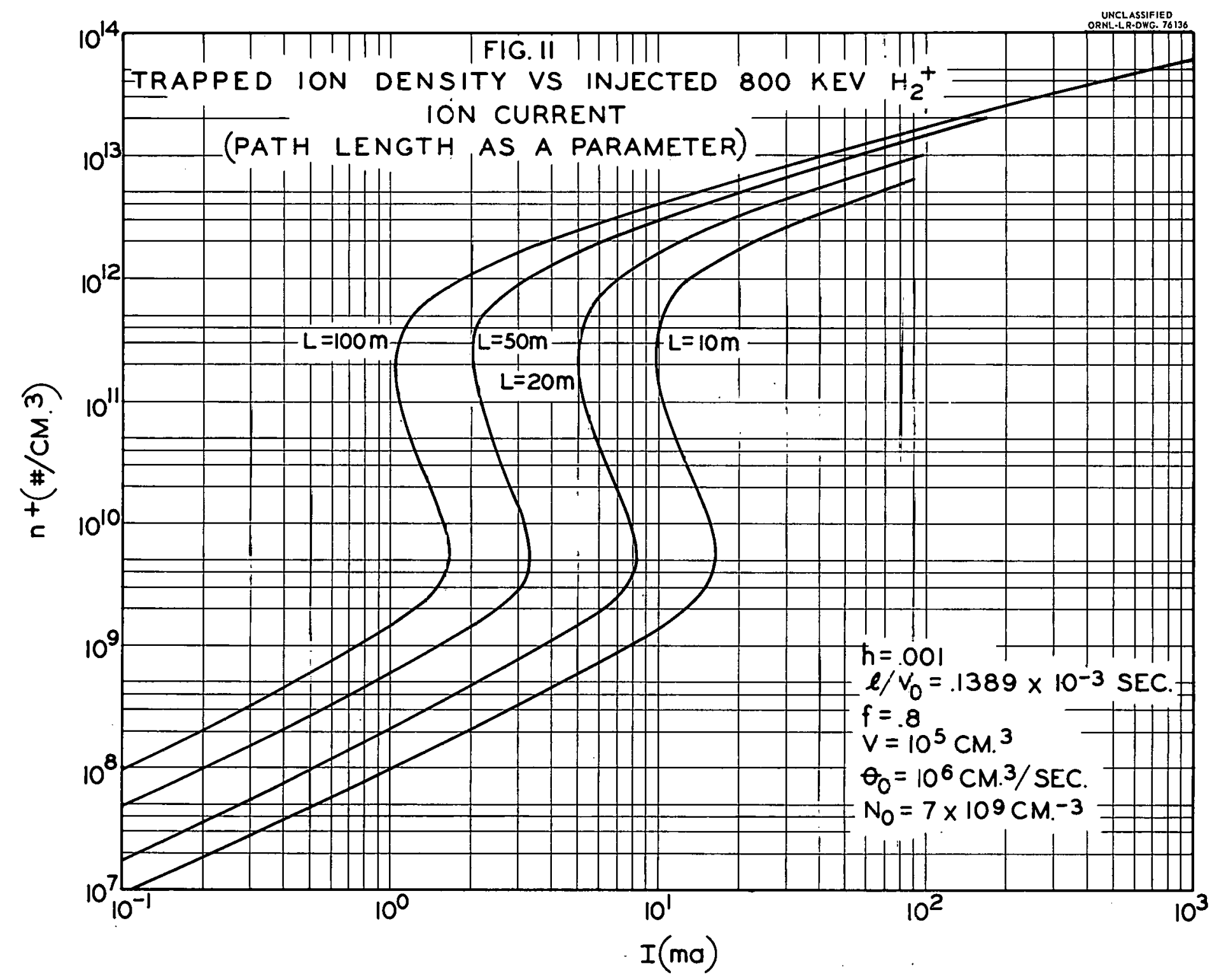




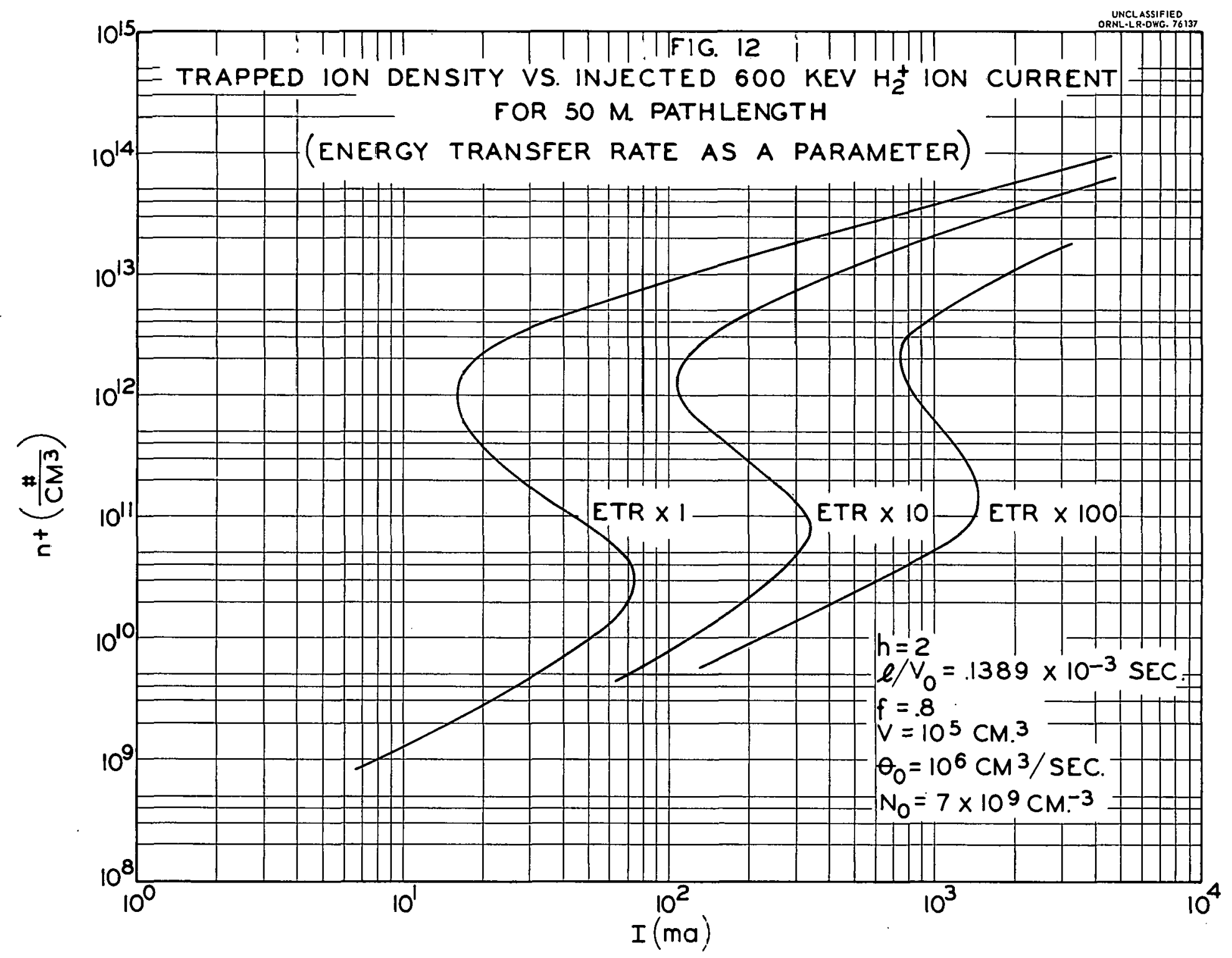


THIS PAGE

WAS INTENTIONALLY

LEFT BLANK 
ORNL-3387

UC-20 - Controlled Thermonuclear Processes TID-4500 (18th ed.)

\section{INTEERAL DISTRIBUTION}

1. Biology Library

2-3. Central Research Library

4. Reactor Division Library

5-6. ORNL - Y-12 Technical Library Document Reference Section

7-26. Laboratory Records Department

27. Laboratory Records, ORNL R.C.

28. P. R. Bell

29-33. T. K. Fowler

34. C. E. Larson

35. N. H. Lazar

36. J. R. McNally, Jr.

37. J. F. Potts

38-42. M. Rankin

43. M. J. Skinner

44. A. H. Snell

45. R. A. Strahlow
46. J. A. Swartout

47. A. M. Weinberg

48. W. P. Allis (consultant)

49. W. R. Chambers (consultant)

50. E. Creutz (consultant)

51. J. W. Flowers (consultant)

52. E. G. Harris (consultant)

53. G. W. Hoffman (consultant)

54. D. W. Kerst (consultant)

55. E. D. Klema (consultant)

56. E. W. McDaniel (consultant)

57. W. B. Pardo (consultant)

58. H. S. Robertson (consultant)

59. D. J. Rose (consultant)

60. J. D. Tillman (consultant)

61. L. P. Smith (consultant)

\section{EXXTERNAL DTSTRTIBUTTON}

62. M. B. Gottlieb, Princeton University

63. E. P. Gyftopoulos, Massachusetts Institute of Technology

64. W. Heckrotte, Lawrence Radiation Laboratory

65. J. M. B. Kellog, Los Alamos Scientific Laboratory

66. A. C. Kolb, Naval Research Laboratory

67. R. W. Mackin, Jr., Jet Propulsion Laboratory

68. J. A. Phillips, Los Alamos Scientific Laboratory

69. R. F. Post, Lawrence Radiation Laboratory

70. L. Spitzer, Jr., Princeton University

71. E. Teller, University of California

72. C. M. Van Atta, Lawrence Radiation Laboratory

73. H. S. Morton, Research and Development Division, AEC, ORO

74. A. Simon, General Atomic Division

75-76. Controlled Thermonuclear Branch, AEC, Washington (1 copy each to A. E. Ruark and H. S. Morton)

77. Research and Development Division, AEC, ORO

78-681. Given distribution as shown in TID-4500 (18th ed.) under Controlled Thermonuclear Processes category (75 copies - OTS) 